\title{
La perspectiva de nuestro país
}

\author{
Por: Sandra de Barraza*
}

\begin{abstract}
El análisis sobre las perspectivas del pais en el corto plazo. merecen reflexionar sobre cinco áreas: una democracia en proceso; la concentración de recursos y oportunidades; el crecimiento urbano y el ordenamiento territorial; nuestro principal producto de exportación; y los principales retos.
\end{abstract}

\section{Una democracia en proceso}

$\mathrm{D}$ urante 15 meses la nación vivirá un largo proceso electoral. El primer ejercicio inició con las elecciones de diputados y de Concejos municipales, de Marzo de 2003. los resultados serán claves durante el riempo que resta de la administración del Gobierno Central (1999/2004), porque en este periodo el tema priorizado por el gobierno de El Salvador, la negociación del Tratado de Libre Comercio USA / Centroamérica (CAFTA), tendrá vicisitudes dependiendo de la correlación de fuerzas en la nueva Asamblea Legislativa.
Los partidos politicos iniciaron la carrera electoral en octubre del año pasado. La campaña se realizó, aún en contra de las normas que dicta la normativa electoral, con la aprobación o con la indiferencia del Tribunal Supremo Electoral (TSE), instancia responsable de regular y organizar las campañas electorales, sin embargo al interior de esta institución los intereses de los partidos politicos mayoritarios se sobreponen a la misión de mantener y fortalecer la credibilidad del sistema.

El segundo ejercicio, será la elección del Presidente del Organo Ejecurivo. El futuro evento adquiere relevancia al interior de todos los partidos políticos, especialmente de los dos

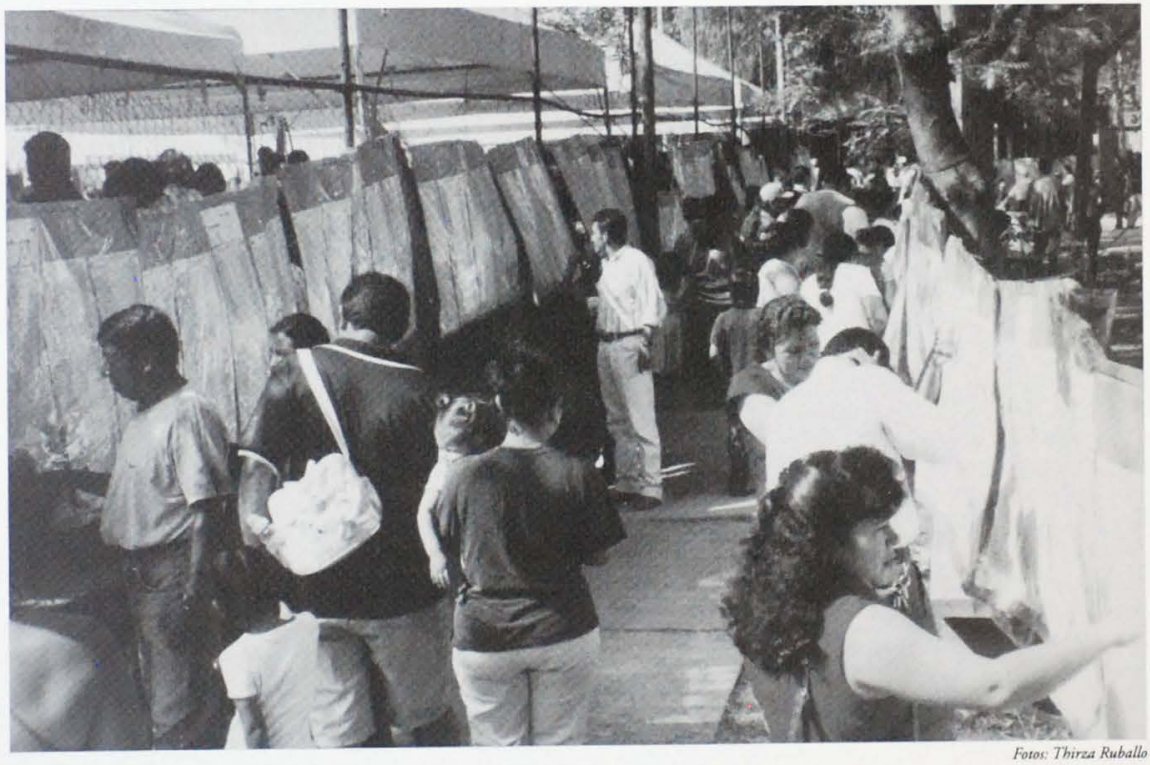


La perspectiva de nuestro pais

mayoritarios, en donde ya se especulan nombres de potenciales aspirantes.

La siguiente administración del gobierno central será determinante para el desarrollo, la gobernabilidad y la credibilidad. En primer lugar, porque tendrá la responsabilidad de crear condiciones para asegurar que todos los sectores tienen oportunidades con los instrumentos comerciales que se negocian en los tratados de libre comercio actualmente, y de esa manera convencer a los legisladores para que los acuerdos alcanzados se racifiquen después de larguísimas y costosísimas conversaciones.

El próximo Presidente también deberá asumir el nuevo puerto La Unión (antes Cutuco). Este puerto estará en plena construcción y suponemos que el gobierno saliente habrá previsto los recursos necesarios para las inversiones complementarias que asegurarán el éxito del proyecto. Caso contrario, el nuevo mandatario tendrá que negociar recursos para cubrir los déficit de saneamiento ambiental y de servicios claves para el desarrollo de la región de oriente.

Debemos tomar en cuenta que al finalizar el actual gobierno se contará con estudios millonarios de los que derivan decisiones que habrán de tomarse. Entre estos estudios destacan, el Plan Nacional de Desarrollo y Ordenamiento. Territorial (PNDOT), auspiciado por el Ministerio de Medio Ambiente y Recursos Naturales (MARN) y por el Viceministerio de Vivienda y Desarrollo Urbano (VMVDU); y por otra parte, dos estudios apoyados por la Agencia Internacional de Cooperación de Japón (JICA): el Estudio de Desarrollo Económico enfocado en la Región de Oriente y la investigación sobre el Proyecto del Complejo Hidroeléctrico del Rio Torola.

Este ambiente electoral que se mantendrá en los siguientes meses no es el imaginado hace once años, cuando se suscribieron los acuerdos de paz. No hemos logrado estructurar el sistema político que refleje el espíritu democrático y compromiso con la representación de los intereses de la ciudadanía o la rendición de cuentas y la transparencia. Esto explica que durante la campaña electoral de marzo del 2003 hayan prevalecido la indiferencia y la apatía de la gente, tal como mostraron las encuestas divulgadas por las universidades José Simeón Cañas, Tecnológica y Francisco Gavidia y por la empresa Cid Gallup.

El problema, visto de esta manera, no es la diferencia de puntos entre candidatos o partidos. El verdadero problema se encuentra en la disminución del porcentaje de población con opción y decisión política-partidaria. Los partidos más grandes han perdido, con relación a las elecciones pasadas,

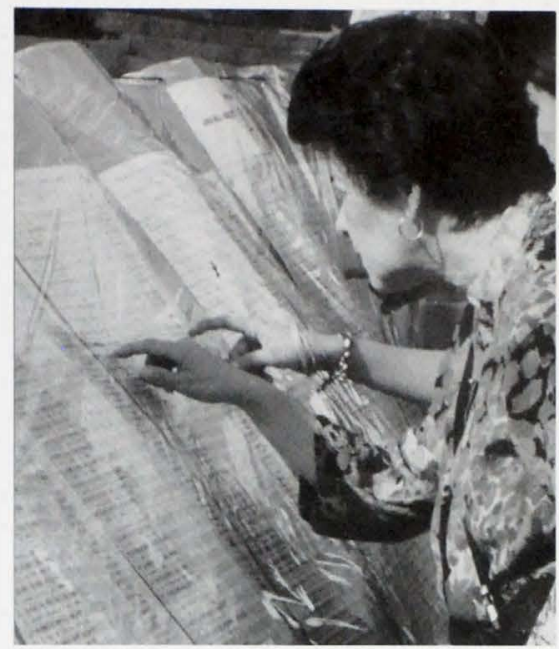

más del 15 por ciento del electorado. $\mathrm{Y}$ esto es grave para nuestra frágil democracia.

La explicación para esta situación es ni más ni menos la ineficacia del sistema político. La población, simple y sencillamente no ve, no reconoce y no siente representados sus intereses en las personas que ocupan las curules en la Asamblea Legislativa. En general puede afirmarse que los partidos políticos seleccionan para cargos de elección popular a personas sin criterio, opinión ni propuesta y de alli deriva la indiferencia y la falta de identificación y compromiso con los problemas e intereses nacionales de los que dicen representar "los intereses del pueblo".

Recordemos que el artículo 85 de la Constitución de la República establece que el sistema político pluralista se expresa por medio de los partidos políticos y que éstos son el único instrumento para el ejercicio de la representación del pueblo dentro del gobierno. Cuando se dictó esta condicionalidad estábamos en guerra y por eso tuvo la intención de evitar a toda costa, que los grupos en armas asumieran el gobierno. Es decir, el arcículo 85 se planteó como un candado para la pretensión de llegar al poder por la vía armada.

A 11 años de firmada la paz es una obligación revisar y modificar el contenido de dicho artículo; además debemos advercir la necesidad de superar el doble candado que los legisladores establecieron con el artículo 248 ya que instituye que "no podrán reformarse en ningún caso, los artículos que 
Universidad Tecnológica de El Salvador

La perspectiva de nuestro país

se refieren a la forma y sistema de gobierno (del 83 al 89 ), al territorio de la República y a la alternabilidad en el ejercicio de la Presidencia de la República". En consecuencia, estamos obligados a asegurar que los partidos funcionan como tal, que los políticos son los mejores, que los candidatos a puestos de elección popular son los más comperitivos y que cleginos con nombre, apellido, formación, compromiso y proyección. Esto significa que debenos hacer las reformas pertinentes y que no tenemos un tiempo ilimitado: de lo contrario el colapso de la democracia es una potencial perspectiva.

\section{La concentración de recursos y oportunidades}

$\mathrm{L}$ a histórica tendencia hacia la concentración de recursos y oportunidades en la Región Metropolitana de San Salvador no se ha modificado; más bien se ha intensificado en detrimento de un desarrollo equilibrado en el ámbito territorial. Las cifras sobre inversión pública, el número de empresas formalmente registradas en el Ministerio de Hacienda como contribuyentes fiscales y la recaudación fiscal, reflejan que San Salvador y La Libertad son los departamentos más favorecidos y en ambos, un número limitado de municipios registran las tasas más altas en los tres aspectos mencionados. Ante esto, los US\$172,7 millones disponibles en el Fondo de Desarrollo Social (FODES) para las transferencias a las alcaldias municipales y los US\$71 millones del Fondo de Conservación Vial (FOVIAL), son insuficientes como inserumentos para superar el desequilibrio territorial.

Los criterios de distribución del FODES afectan al municipio de San Salvador, del 6 por ciento que deternina la ley recibe un monto menor de transferencia que cuando el monto se limitaba al 1 por ciento del presupuesto de la nación, es un hecho que como instrumento financiero no permite crear condiciones para el desarrollo en municipios con indicadores desfavorables. Y esto es así, porque en estos municipios la capacidad de recaudación fiscal por la vía impositiva o tasas municipales es escasa o nula porque carecen de base empresarial.

Adicionalmente y no obstante que muchos municipios atraen a la cooperación internacional bilateral o multilateral, por su condición de pobreza la agenda se orienta hacia los proyectos de carácter distributivo como servicios básicos o infraestructura social y no para crear condiciones que construyan entornos de competitividad en el territorio.

De cara al futuro, entonces, es indispensable profundizar esfuerzos para impulsar la micro regionalización y la asocia- ción de municipios como condición necesaria para lograr una visión integral de desarrollo, un aprovechamiento estrarégico y eficaz de los recursos, y sobre todo, capacidad de participación e injerencia en el uso del financiamiento de proyectos adicionales para el desarrollo local.

Simultáneanente es también indispensable repensar los criterios de asignación del FODES si real y efectivamente se quiere descentralizar las oportunidades de desarrollo en el país. Es importante reflexionar sobre el significado que ticne una transferencia de US\$8 millones para una alcaldia de la región metropolitana e imaginar et impacto que tendria una inversión de esta magnitud en una microregión del norte de Morazán o l.a Unión.

Así, para desceneralizar las oportunidades debemos repensar el ordenamiento territorial del pais, evaluar y definir las atribuciones y comperencias de los gobiernos locales y sobre esta base, diseñar una nueva clasificación de municipios para los efectos de transferencia de fondos y responsabilidades. Por ejemplo, los municipios que se consideren del tipo " $\mathrm{A}$ " porque tienen más de 100 mil habitantes y cuentan con una base empresarial instalada y financian su presupuesto de gasto c inversión en un 80 por ciento con recaudación fiscal, de-

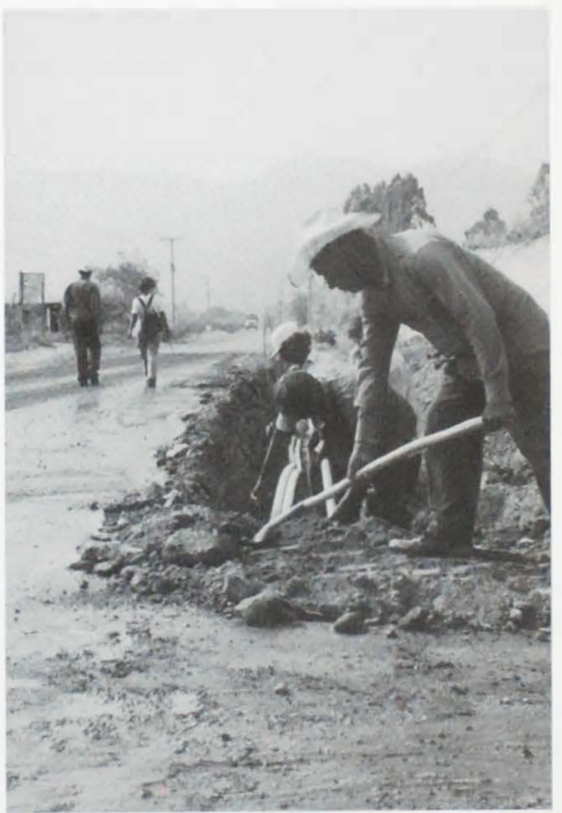


La perspectiva de nuestro pais

\section{Tipología de municipios}

\begin{tabular}{|l|l|l|l|l|l|}
\hline & Tipo 1 & Tipo 2 & Tipo 3 & Tipo 4 & Tipo 5 \\
\hline Población & 150,738 & 81,793 & 21,466 & 13.954 & 9,277 \\
\hline Grado de urbanización & $77 \%$ & $65 \%$ & $40 \%$ & $29 \%$ & $21 \%$ \\
\hline INB1 & 15 puntos & 27 puntos & 40 puntos & 46 puntos & 58 puntos \\
\hline Población toral & $1,658,124$ & $1,145,113$ & $1,395.328$ & $1,437.352$ & 640,120 \\
\hline Extensión territorial & $396 \mathrm{Km} 2$ & $1,817 \mathrm{Km} \mathrm{2}$ & $5,175 \mathrm{Km} 2$ & $8,405 \mathrm{Km} 2$ & $5,2512 \mathrm{Km} 2$ \\
\hline Número de municipios & 11 & 14 & 65 & 103 & 69 \\
\hline
\end{tabular}

Fuente: PROMUDE/GTZ: Propuesta de una Tipología de Municipios para El Salvador, enero 2002

berian de asumir todas y cada una de las atribuciones y competencias que establece el Código Municipal. Existen 13 municipios ( $5 \%$ del total nacional) que tienen dicho perfil y por tanto, podriamos asegurar que son expresiones reales de la autonomía de los gobiernos municipales.

Pero aquellos municipios clasificados como tipo $E$, es decir que no tienen más de 5 mil habitantes, que dependen en un cien por cien del FODES porque no cuentan con recaudación fiscal ya que no tienen a quien cobrarle, $y$ acceden a la asistencia de la cooperación internacional, cuyo número asciende a 59 ( $23 \%$ del total nacional), deben ser objeto de revisión de sus competencias y atribuciones; así, se aseguraría el cumplimiento de la ley que establece la obligatoriedad del gobierno central de asumir aquellas para las cuales los municipios no están capacitados o no tienen recursos para cumplirlas.

El país cuenta con información importante para superar el discurso sobre descentralización y avanzar eficazmente en el proceso. Para el caso, el programa PROMUDE de la Cooperación Técnica Alemana (GTZ) publicó recientemente la Propuesta de Tipología de Municipios que es un aporte para tomar decisiones técnicas y políticas (ver siguiente cuadro) Si continuamos abordando el tema como hasta la fecha, es decir, de manera superficial pero con estrategias orientadas a fortalecer la concentración, diff́cilmente lograremos tener un territorio más equilibrado. Es un riesgo que debemos enfrentar $y$ resolver en el corto plazo.

\section{Distribución de municipios según población}

\begin{tabular}{|l|c|}
\hline Población & No. de municipios \\
\hline Menos de 5,000 & 9 \\
\hline 5,000 a 9,999 & 67 \\
\hline 10,000 a 19,999 & 63 \\
\hline 20,000 a 99,999 & 60 \\
\hline 100,000 y mís & 13 \\
\hline Total & 262 \\
\hline
\end{tabular}

Fuente: elaboración propia con datos de DIGESTYC; 1992

\section{El crecimiento urbano y el ordenamiento territorial}

omando en cuenta el nivel de desarrollo, la territorial en el ámbito urbano, el Plan Nacional de Desarrollo y Ordenamiento Territorial (PNDOT) ha establecido 31 centros urbanos que se integrarian al sistema de ciudades propuesto inicialmente en las Acciones Territoriales del Plan de Nación (ver siguiente cuadro) .

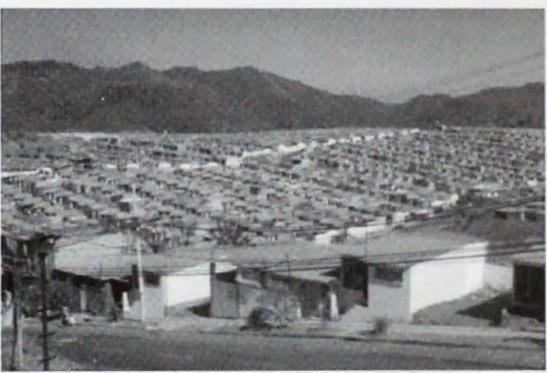

Con este aporte, la visión inicial de crear una red de ciudades desconcentradas, a lo largo y ancho del país, tiene mayor fundamento para hacerle frente a un proceso de urbanización que se ha caracterizado por la improvisación y el desorden que continúa y depende de las iniciativas de construcción de nuevas carreteras. Debemos tomar conciencia que dentro de 12 años la población crecerá en 2.5 millones de habitantes más, que el parque vehicular se incrementará desde $93 \mathrm{mil}$ vehículos ligeros circulando diariamente a $321 \mathrm{mil}$, y por tanto es imprescindible quitar de las manos de los lorificadores la "responsabilidad" de la urbanización porque llegaremos al caos total y la inviabilidad de pais.

El Viceministerio de Vivienda y Desarrollo Urbano (VMVDU) financió con fondos del BID los Planes Maestros de Desarrollo Urbano (PLAMADUR) para las ciudades de San Salvador, Santa Ana, San Miguel, Usulutín y 
Sonsonate. Y también el estudio del Valle de San Andrés. Estos estudios se realizaron durante los años 1995 y 1997 y tuvieron un costo de US\$6,2 millones, los primeros y el del Valle de San Andrés de US\$1.4 millones.

Además, la GTZ financió en 1998 el estudio del plan de desarrollo urbano de Santa Rosa de Lima. Pero, han tenido poca difusión y escasa urilidad para el reordenamiento urbano de las ciudades debido al reducido involucramiento de los actores claves en el proceso, es decir, los gobiernos locales, los empresarios y los habitantes. El que ha tenido mejor suerte es el del Valle de San Andrés porque ha servido para aglutinar a algunos municipios alrededor de una oficina de planificación, centralizada en su gestión pero desconcentrada territorialmente.

Está en proceso una inversión millonaria en la construcción del puerto de La Unión, el que funcionaría como puerto de tercera generación, si se integra con una ciudad competitiva, que cuente con zonificaciones y regulaciones sobre el uso del suelo y con los servicios fundamentales, particularmente el de manejo de desechos sólidos y líquidos. Hay gestiones del VMVDU para superar el vacio de planificación urbana en el espacio conf ormado por los municipios de Conchagua y La Unión, en donde tendrá un impacto inmediato la construcción del nuevo puerto La Unión y que cubren un territorio de $353.5 \mathrm{Km} 2$ y 85 mil habitantes, población que crecerá el 52 por ciento para el año 2015.

\section{Nuestro principal producto de exportación}

Según información del Banco Central de Reserva en el año 2001 el valor total de las exportaciones fue de US\$2,865 millones; cifra que tuvo una reducción de US\$76 millones respecto del año 2000 . El 58 por ciento del valor total de las exportaciones en el año 2001, lo representó la maquila y el principal destinatario de la producción fue Estados Unidos. El mismo año el sector de electricidad atrajo el mayor porcentaje de la inversión extranjera directa (37\%); seguido por la industria manufacturera $(17 \%)$ y las comunicaciones ( $16 \%$ ) La maquila atrajo el 8 por ciento del total nacional. Los principales inversionistas provienen de Estados Unidos, Venezuela, Francia y España.

Las remesas familiares son el rubro que mayor tasa de crecimiento registra. En 1991 el monto fue de US\$790.1 millones; en el año 2001 fue de US\$1,910.5 y fueron superados los US\$2,000.00 millones en el 2002. Las remesas son el reflejo de la emigración de los salvadoreños, fenómeno y proceso que ha sido calificado como la principal política contra la pobreza.

Según la Encuesta de Hogares de Propósitos Múltiples del año 2000 , el 19.7 por ciento de población recibió remesas con un promedio anual por familia de US\$1,448.00 (US\$120.00 mensuales). Si esto se compara con el promedio del salario mínimo que oscila en el orden de los US\$144.00 mensuales y se considera que en el ambiente son escasas las oportunidades de empleo formal, con facilidad se entiende que la principal aspiración de muchos salvadoreños es emigrar al norte enfrentando las iniciativas y esfuerzos coordinados por detenerla, particularmente después de septiembre del 2001 y las acciones terroristas en los Estados Unidos. Mientras la población no tenga oportunidades concretas para desarrollarse dentro del país, la meta seguirá siendo el norte.

En una reciente publicación de FUSADES se analiza el comportamiento de las exportaciones dur ante la década del noventa y afirman que los esfuerzos por reconvertir $y$ ampliar la base exportable no han tenido el éxito que se esperaba. A casi tres décadas de iniciadas las reformas estructurales para lograr una mejor inserción en el mercado mundial, la situación no es la esperada. Lamentablemente lo que se ha conseguido es la expulsión de ciudadanos sin oportunidades. No obstante, en otro ambiente logran una inserción exitosa, y más aún, con su trabajo financian la economía salvadoreña 
La perspectiva de nuestro pais

y han ayudado a disminuir sustancialmente los indices de pobreza, en algunas zonas del pals.

Con esta realidad de la base productiva, con los desaflos que presenta el mercado mundial y con las implicaciones y oportunidades que el CAFTA planteará al pals, es difícil posponer la asunción e impulso de una política y estrategia para la producción que permita acumular riqueza y desarrollo a lo largo y ancho del pals. Y debe recalcarse a lo largo $y$ ancho del pals, porque de lo contrario, aún cuando se logre atraer mayor inversión extranjera al país, se agudizarán los desequilibrios porque el beneficio no se acumula ni se aprovecha para beneficio nacional.

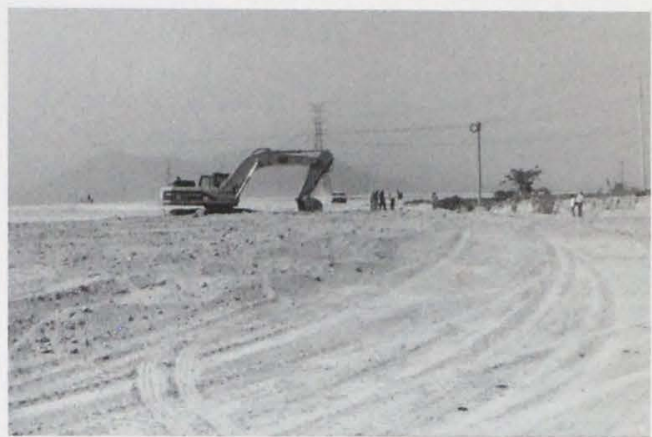

- El tercer reto se refiere a la institucionalidad. La democratización pasa por la eficacia y pertinencia de las atribuciones del Estado en cuanto a asegurar y velar por el bienestar de toda la población. Debemos dar inicio a la revisión, precisión y adecuación de las atribuciones y competencias de los distintos niveles de gobierno (central y local) y sobre este acuerdo, viabilizar el proceso de descentralización como base para la modernización del Estado.

- El cuarto reto se refiere al ordenamiento territorial. Este es la base para el desarrollo de la producción y productividad con relaciones armoniosas con el territorio. El debate sobre el ordenamiento territorial como base para la planificación y la reforma polfrico electoral, son temas que deberán introducirse en la agenda ciudadana y política en el corto plazo.

- Y el quinto reto se refiere a la reforma polírico electoral. Es una tarea ineludible asumir inmediatamente la reforma del sistema electoral para que la democracia no colapse. Supone la revisión de la ley del Tribunal Supremo Electoral y dividir las funciones administrativas y jurisdiccionales; creación de nuevas circunscripciones electorales para asegurar la representatividad de los diputados; creación de una ley de partidos políticos. Los ciudadanos necesitan certeza acerca del sistema político en el sentido de que responde a las aspiraciones de desarrollo y progreso de la nación. presupuesto general de la na prespuesto general de la nación sobre la base de la información disponible en el Plan Nacional de Desarrollo y Ordenamiento Territorial (PNDOT). De igual manera, debemos reestructurar la institucionalidad del país. Estas son decisiones que deben ser asumidas en las esferas de los Organos Ejecurivo y Legislativo. Ventajosamente las decisiones estarán sustentadas en este millonario estudio que está desarrollado el MARN y el VMVDU.

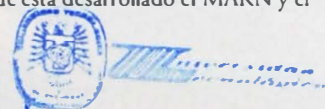

- Sandra de Barraza, analista polftica. directora de la Comisión Nacional para el Desarrollo.

I Franco. Corolina Alas de. Pollirica comercial y evolución del sector axportador duranke Los noventa en EI Salvador, FUSADES. San Saluador. 2002 